\title{
Subsidence rules of underground coal mines for different soil layer thickness: Lu'an Coal Base as an example, China
}

\author{
Haifeng $\mathrm{Hu}^{1} \cdot$ Xugang Lian $^{1}$
}

Received: 31 March 2015/Revised: 30 June 2015/Accepted: 31 July 2015/Published online: 1 October 2015

(C) The Author(s) 2015. This article is published with open access at Springerlink.com

\begin{abstract}
Damage caused by underground coal mining is a serious problem in mining areas in China; therefore, studying and obtaining the rules of ground movement and deformation under different geological conditions is of great importance. The numerical software ANSYS was used in this study to simulate mining processes under two special geological conditions: (1) thick unconsolidated soil layer and thin bedrock; (2) thin soil layer and thick bedrock. The rules for ground movement and deformation for different soil layer to bedrock ratios were obtained. On the basis of these rules, a prediction parameter modified model of the influence function was proposed, which is suitable for different values of unconsolidated soil layer thickness. The prediction results were verified using two sets of typical field data.
\end{abstract}

Keywords Numerical simulation · Ground movement and deformation · Prediction of ground subsidence · Subsidence rules $\cdot$ Ratio of soil layer to bedrock

\section{Introduction}

Underground coal mining causes deformation and movement of strata and ground surface. Some protected objects, such as houses and railways, around the coal panel would be damaged if a mining plan was carried out without considering the consequences. Mining subsidence has been studied for more than 60 years and some general rules have been obtained. Strata with different properties will follow different deformation rules. In this paper, we focused on strata consisting of two types of components: bedrock lying above a coal seam and the unconsolidated soil layer. The ratio of soil layer to bedrock is very important. When the ratio is large, the soil layer is thick and the bedrock is thin; if the ratio is small, the soil layer is thin and the bedrock is thick. The numerical simulation software ANSYS was used to analyze the ground deformation and movements of

Haifeng $\mathrm{Hu}$

tyhhf65@163.com

1 College of Mining Engineering, Taiyuan University of Technology, Taiyuan 030024, China underground mining for different values of the soil layer to bedrock ratio. A prediction model using an influence function was used in this paper to model the subsidence for different soil layer thickness.

Numerical simulation is an effective way to analyze geotechnical engineering mechanics. A number of previous studies of mining subsidence have used numerical simulation software. For example, on the basis of the specific geological and mining conditions of certain coal panels in China, a series of numerical models for different unconsolidated layer thicknesses were established using the simulation software FLAC3D. The relationship between unconsolidated layer thickness and surface movement was studied (Dai et al. 2011). Based on mining under thick unconsolidated layers and the specific geological conditions, a numerical model of strip mining under thick unconsolidated layers was established, and the rules of ground movement for this condition were established (Xu and $\mathrm{Li}$ 2012). A numerical model using the finite difference method to simulate the safety problems of a dam near the Wutong coal mine area induced by underground mining was constructed. Four scenarios were simulated in the Wutong coal mine area, the best choice being the model in 
which the nearest distance from the boundary of the surface movement area to the edge of the foundation is $35 \mathrm{~m}(\mathrm{Xu}$ and Kulatilake 2013). By studying the regularity of strata movements in deep mining, a coupled model involved unconsolidated layer and bedrock of deep mining strata composite medium was obtained. Deep mining was simulated using FLAC3D, and the coupling relationship between unconsolidated layer and bedrock was analyzed in strata composite layer (Yang and Chen 2011). Coal mine subsidence was simulated using the CSIRO Exploration and Mining software COSFLOW. In addition to the major benefits compared to conventional continuum numerical models of sedimentary rock, this software is able to simulate rock breakage and slip efficiently as well as separation along bedding planes (Guo et al. 2004). ANSYS was used to simulate the dynamic changes and tendency of overburden movement and bed development during strip mining and stopping under railways. The results showed that movement and rheological changes in key strata are some of the major causes of surface subsidence and induced deformation of surface railways (Wang et al. 2008). Using actual project data, the rules governing displacement and deformation damage of overlying strata and the surface were obtained using FLAC3D, and a reasonable strip mining method and interrelated parameters were presented for the specific geological and mining conditions of coal. In addition, some research has been carried out using an influence function prediction model in conditions with a thick soil layer (Ji and Yu 2011). The mechanism of surface subsidence caused by pressure consolidation of loose layers has been explored. If the loose layer is significantly thick, it is inevitable that pressure consolidation of a water-bearing loose layer or deformation of the soil body will cause additional stress in the mining soil body, and dissipation of the excess pore water pressure will result in consolidation. Using the surface subsidence features of thick loose layers in mining areas, a correction model has been applied using the probability integral method to predict subsidence with satisfactory predictive results (Zhang et al. 2012). Based on the conditions of the Huainan coal mining area in China, by combining physical simulation, theoretical analysis and experimental data, the subsidence mechanism induced by underground mining of thick unconsolidated soil layer was studied, and a prediction model for this condition was established (Zhou et al. 2014). Quantitative prediction of mining subsidence under thin bedrock and a thick unconsolidated layer was obtained by means of artificial neural networks (ANN). The improved neural network was used for modeling and predicting mining subsidence. The ANN output can reflect changes in the trends of ground movement and deformation. The forecast results are in good agreement with actual observations (Yang and Xia 2013).
Previous studies have dealt with the general rules of ground movement for different strata conditions based on simulation software and analysis of field data, which obviously addresses the influence of bedrock and the unconsolidated layer. However, previous research did not directly transfer the rules of mining under unconsolidated layer and bedrock to the classic influence function of mining subsidence prediction, and the research results cannot be used to predict the value of surface movement and deformation. In this study, different ratios of soil layer and bedrock are added to the influence-function prediction method: this study is the first time that this has been done. In this paper, the ground movement rules for different geological conditions are studied in Sects. 1 and 2 and the prediction model were described in Sect. 3.

\section{Numerical simulation of two typical geological conditions of underground coal mines in Lu'an Coal Base}

\subsection{Thick soil layer and thin bedrock}

In the numerical simulation based on the Sima coal mine in Southern Shanxi, China, the key parameters of the selected geological section were: mining depth $200 \mathrm{~m}$, mining height $6.7 \mathrm{~m}$, bedrock thickness $20 \mathrm{~m}$, soil layer thickness $180 \mathrm{~m}$, and a horizontal coal seam.

The model set up was as follows: model size $600 \mathrm{~m} \times 216.7 \mathrm{~m}$, extracted zone size $164 \mathrm{~m} \times 6.7 \mathrm{~m}$, and mining height $6.7 \mathrm{~m}$. At the bottom boundary of the model, a displacement of zero was applied in the vertical direction, and at the left and right boundaries a displacement value of zero was applied in the horizontal direction. A gravity value of $9.8 \mathrm{~m} / \mathrm{s}^{2}$ was applied over the whole model. The physical and mechanical parameters of the direct roof and the strata above the coal seam were obtained from rock and mechanical tests of field drill cores.

Figures 1 and 2 show the horizontal and vertical displacement contours in bedrock and the unconsolidated soil layer after extraction. Figures 3 and 4 show the horizontal and vertical displacement curves of the ground after extraction. From Figs. 2 and 4, the results of the model are that the ground maximum subsidence is $20.327 \mathrm{~m}$ under gravity loading. After the coal has been extracted, the ground maximum subsidence is $26.564 \mathrm{~m}$, meaning that the practical maximum ground subsidence is $6.237 \mathrm{~m}$ in the middle of the goaf. As illustrated in Fig. 3, the maximum horizontal movement is $1.344 \mathrm{~m}$, which occurs at both sides of the goaf approximately $120 \mathrm{~m}$ from the goaf center, and approximately $38 \mathrm{~m}$ outside the boundary of the goaf. In general, the maximum ground horizontal movement occurs immediately above the inflexion point of 


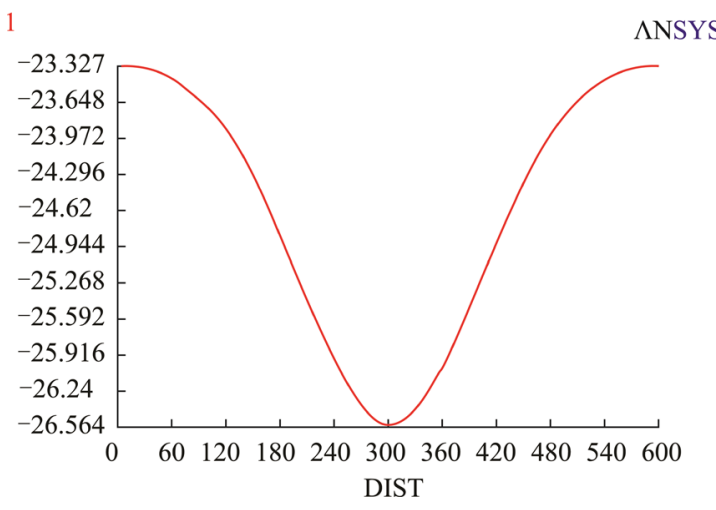

Fig. 1 Curve of ground vertical displacement after extraction in the Sima coal mine

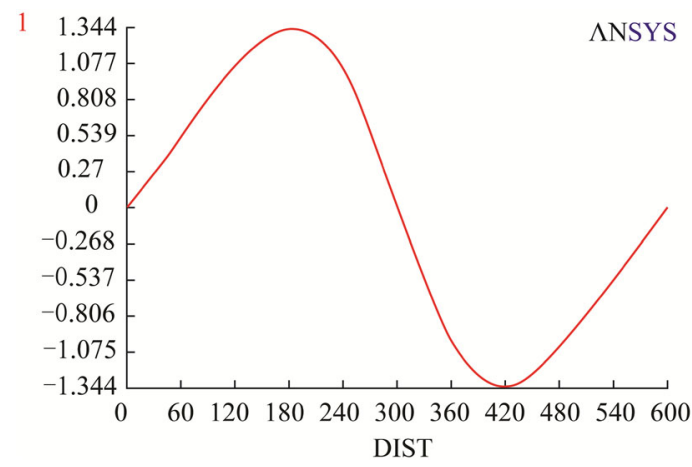

Fig. 2 Curve of ground horizontal displacement after extraction in the Sima coal mine

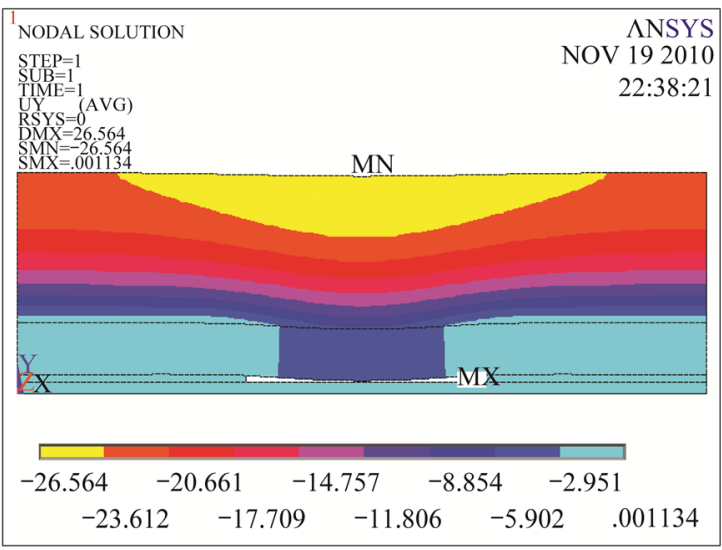

Fig. 3 Contours of vertical displacement after extraction in the Sima coal mine

the ground subsidence basin. Because the inflexion point moves outside of the goaf, the ground movement within the basin is gentle and the range of movement is increased. Thus, compared with mining in normal geotechnical conditions, in conditions with a thick soil layer and thin

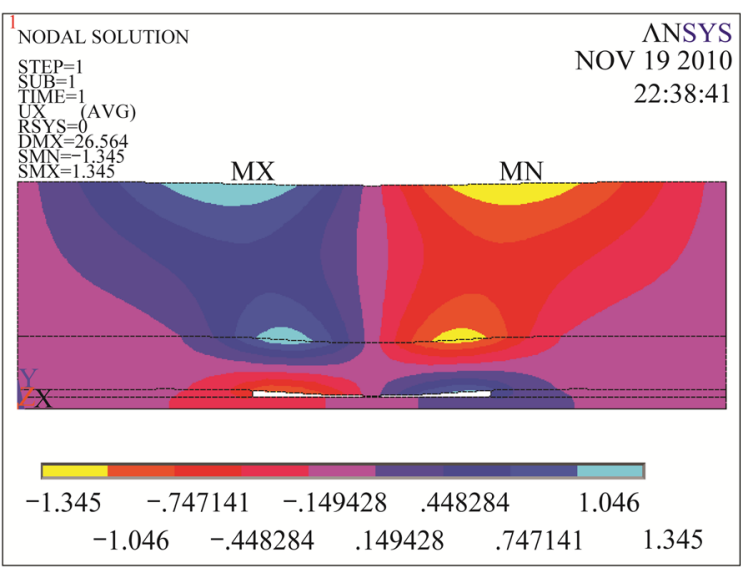

Fig. 4 Contours of horizontal displacement after extraction in the Sima coal mine

bedrock, both the range of ground movement and the maximum subsidence are increased.

\subsection{Thin soil and thick bedrock}

This model was based on the Wuyang coal mine in southern Shanxi Province, China. A section of the geology of this mine was used in the simulation. The key parameters of the selected geological section were as follows: mining depth $242 \mathrm{~m}$, mining height $6 \mathrm{~m}$, bedrock thickness $212 \mathrm{~m}$, soil layer thickness $30 \mathrm{~m}$, and the coal seam was horizontal.

The model size was $800 \mathrm{~m} \times 268 \mathrm{~m}$, the extracted zone size was $180 \mathrm{~m} \times 6 \mathrm{~m}$, and the mining coal seam height was $6 \mathrm{~m}$. The boundary limitation and gravity setup of this model were the same as those of the model described in Sect. 2.1.

As illustrated in Figs. 5 and 6, after coal extraction the maximum ground subsidence above the goaf is $1.397 \mathrm{~m}$. Subtracting the subsidence before extraction caused by gravity loading yields a practical maximum ground

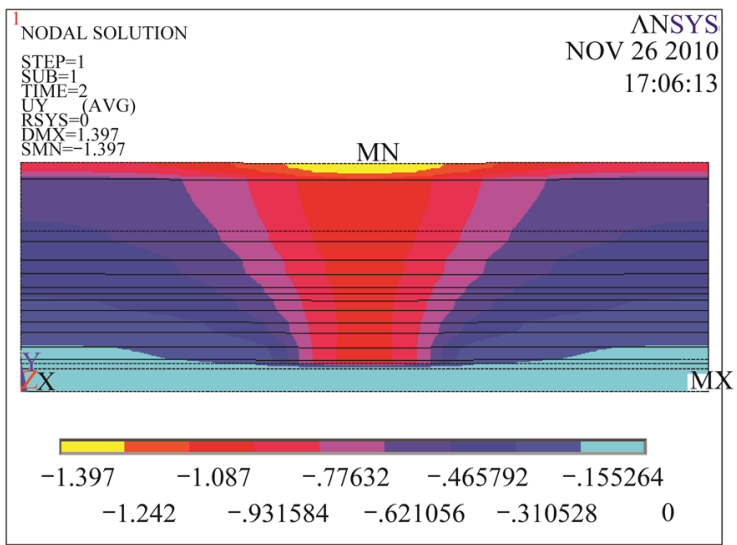

Fig. 5 Contours of vertical displacement after extraction in the Wuyang coal mine 


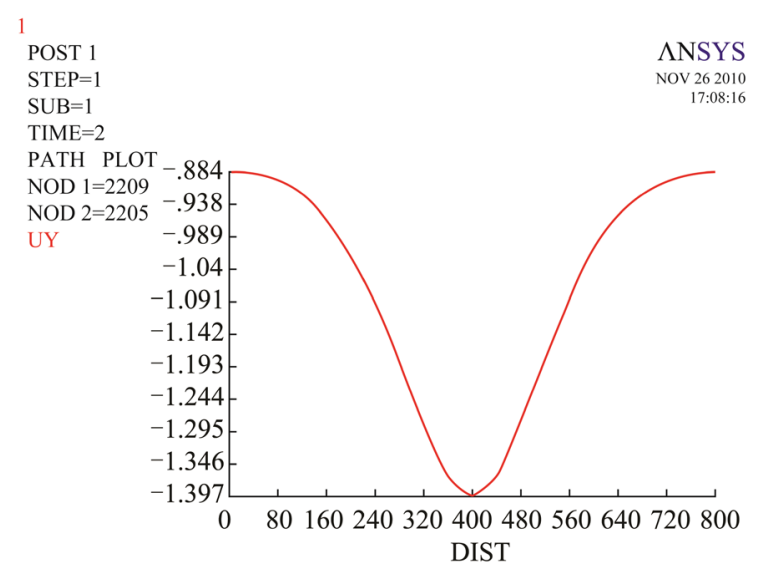

Fig. 6 Curve of ground vertical displacement after extraction in the Wuyang coal mine

subsidence of $0.508 \mathrm{~m}$. As illustrated in Fig. 5, the vertical displacement contour is steeply inclined which is different from the results for the thick soil layer and thin bedrock shown in Fig. 1. In the Wuyang coal mine, the surface soil layer is very thin or thinned out and the slope of the surface basin is steeply inclined.

Figures 7 and 8 showed the maximum horizontal movement is $0.233 \mathrm{~m}$ and is located approximately $30 \mathrm{~m}$ outside the boundary of the goaf. The range of significant influence is much smaller than that of the model described in Sect. 2.1.

\section{Ground mining subsidence rules for different soil layer and bedrock thickness}

\subsection{Simulation of different thicknesses of unconsolidated soil layer}

When the bedrock thickness is constant, the ground movement and deformation rules change as the thickness

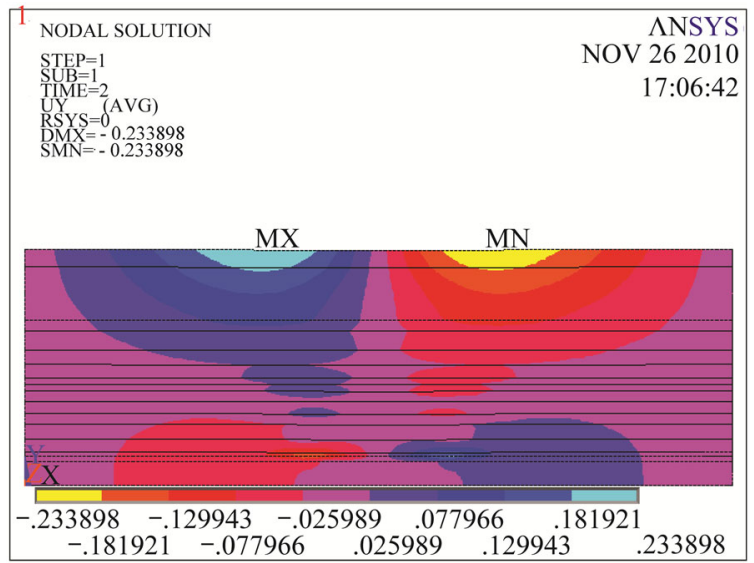

Fig. 7 Contours of horizontal displacement after extraction in the Wuyang coal mine

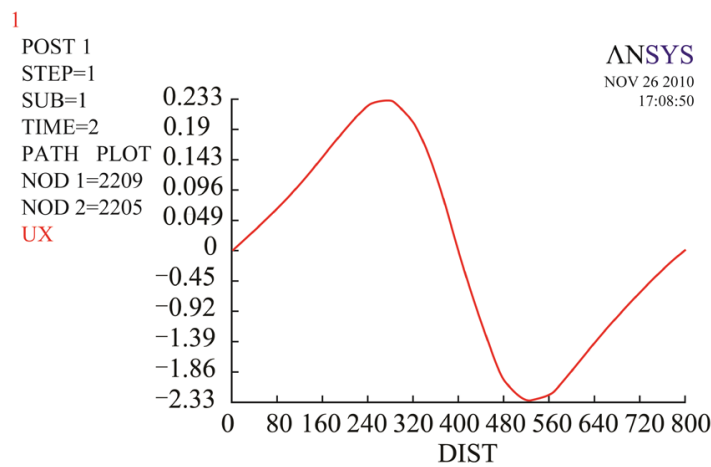

Fig. 8 Curve of ground horizontal displacement after extraction in the Wuyang coal mine

of the soil layer alters. To study the rules of ground subsidence in conditions of different soil layer thickness, models were established with constant bedrock thickness and variable soil layer thickness. The length of the panel was $200 \mathrm{~m}$, the mining coal seam height was $7 \mathrm{~m}$, the bedrock thickness was $80 \mathrm{~m}$, and the thickness of the unconsolidated soil layer ranged from 20 to $200 \mathrm{~m}$ in $20 \mathrm{~m}$ increments.

The subsidence and horizontal displacement curves of ground points for different soil layer thicknesses are drawn in Figs. 9 and 10.

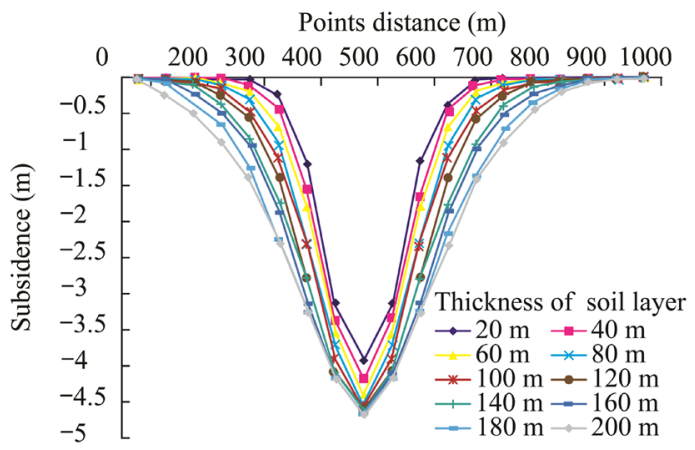

Fig. 9 Ground subsidence curves for different soil layer thickness

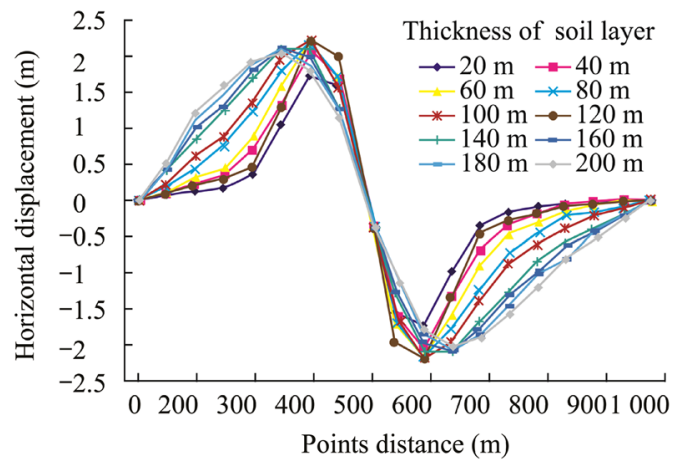

Fig. 10 Ground horizontal displacement curves for different soil layer thicknesses 
When the bedrock of the model is of constant thickness, as the soil layer thickness or the soil layer to bedrock ratio increases, the subsidence curve changes from steeply inclined to flat, the range of movement deformation expands, and the amount of subsidence and the subsidence factor both increase (Fig. 9). Figure 10 shows that the position of maximum horizontal displacement is not changed, but the values outside the boundaries of goaf are increased. The maximum subsidence point is in the centre of the goaf, and the points of maximum horizontal displacement are at the two side boundaries of the goaf.

The curves of maximum subsidence and horizontal displacement with different soil layer thicknesses (Figs. 11 and 12) reveal some rules of ground movement and deformation.

(1) With increasing soil layer thickness, the ground maximum subsidence describes a logarithmic curve (Fig. 11): for soil layers 20-100 m thick the maximum subsidence increases very quickly, but for thicknesses greater than $100 \mathrm{~m}$ the maximum subsidence increases very slowly.

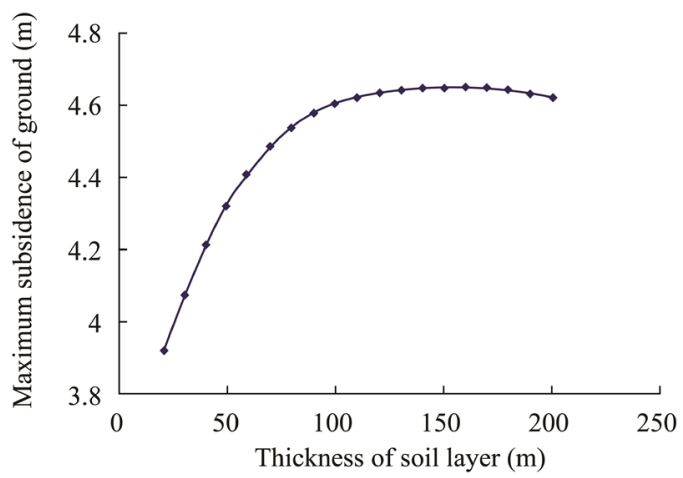

Fig. 11 Relationship between maximum subsidence and soil layer thickness

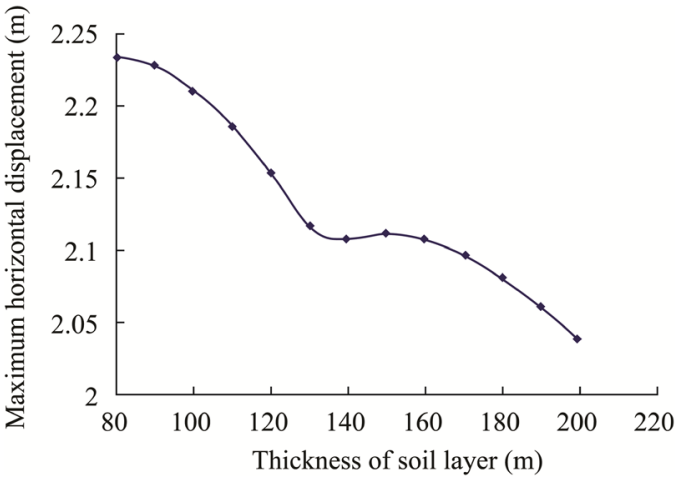

Fig. 12 Relationship between maximum displacement and soil layer thickness
(2) With increasing soil layer thickness, the ground maximum horizontal displacement forms a periodic linearly declining curve (Fig. 12): for soil layer thicknesses between 20 and $130 \mathrm{~m}$, the displacement values decline linearly; between 130 and $160 \mathrm{~m}$, the curve flattens out; and after $160 \mathrm{~m}$, the values again show a linear decrease.

\subsection{Simulation of different bedrock thicknesses}

When the thickness of the unconsolidated soil layer is constant, the ground deformation and movement rules alter with changes in the bedrock above the coal seam. To study the subsidence rules for different thicknesses of bedrock, a numerical simulation model with constant soil layer thickness and changing bedrock thickness was set up. The model assumptions were that the mining coal seam height was $7 \mathrm{~m}$, the panel length was $200 \mathrm{~m}$, the thickness of the unconsolidated soil layer was $20 \mathrm{~m}$, and the bedrock thickness was $80-160 \mathrm{~m}$ in increments of $10 \mathrm{~m}$.

The curves of ground subsidence and horizontal displacement plotted against bedrock thickness are shown in Figs. 13 and 14. Figures 15 and 16 contain the curves of

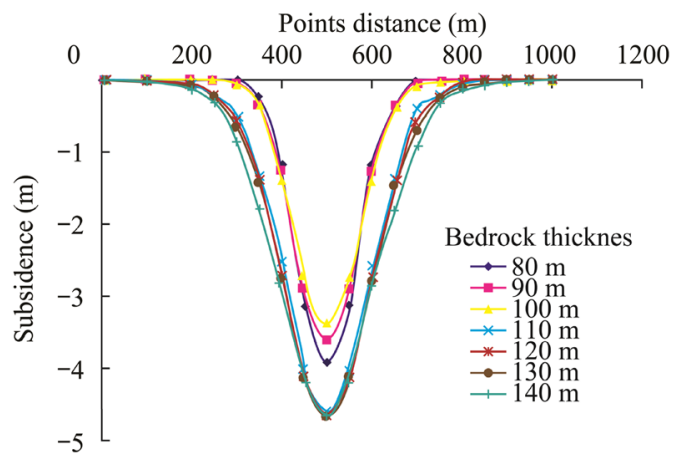

Fig. 13 Ground subsidence curves for different bedrock thicknesses

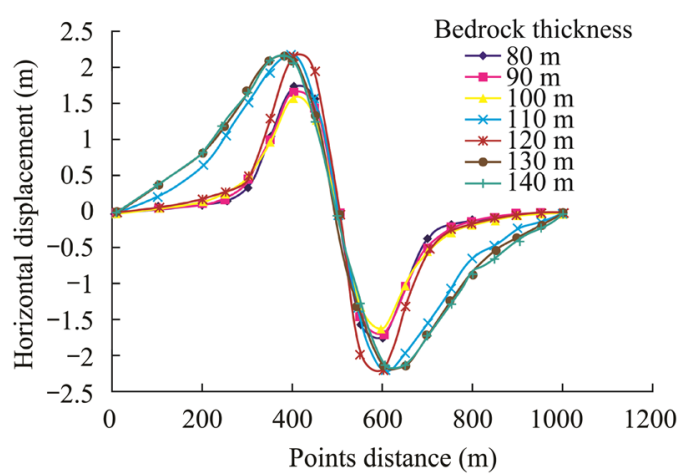

Fig. 14 Ground horizontal displacement curves for different bedrock thicknesses 


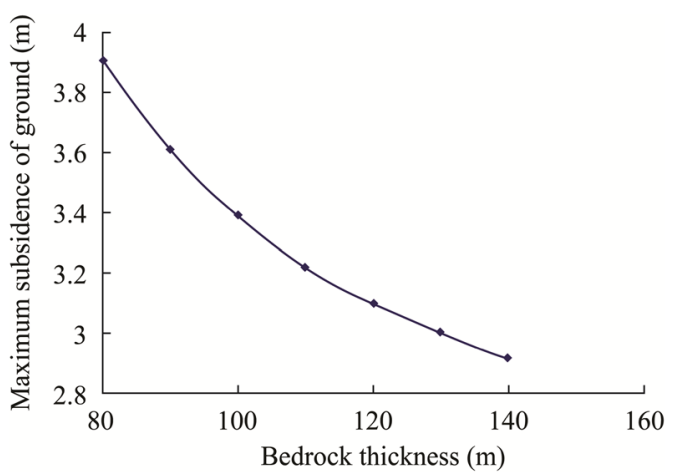

Fig. 15 Relationship between maximum ground subsidence and bedrock thickness

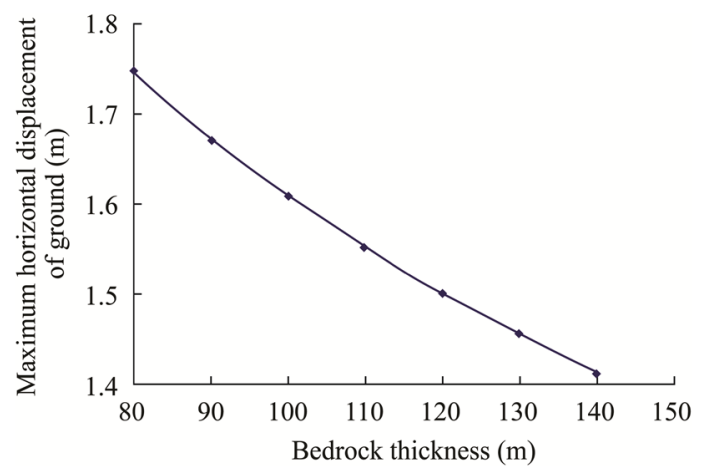

Fig. 16 Relationship between maximum ground displacement and bedrock thickness

maximum subsidence and maximum horizontal displacement plotted against bedrock thickness. The simulation results demonstrate that ground movement and deformation are negatively correlated with bedrock thickness, i.e., when the bedrock is thin the ground movement and deformation are large; when the bedrock is thick the ground movement and deformation are small. The ground maximum subsidence and maximum horizontal displacement decrease as bedrock thickness increases, and the relations between them are negative exponential curves, as illustrated in Figs. 15 and 16.

\section{Influence function prediction method on the soil layer to bedrock ratio}

The influence function is a general prediction method for strata and ground movement induced by underground coal mining and is suitable for general geological conditions such as when the soil layer is very thin or absent. However, for a very thick soil layer this prediction method has some limitations, for example, it cannot be used to obtain large subsidence factors and a large range of ground movement. The mechanics of mining subsidence are different for the soil layer and for the bedrock.

\subsection{Prediction parameters of the influence function modified for a thick unconsolidated soil layer}

(1) Main influence radius $r$

$r=\frac{H_{s}}{\tan \varphi}+\frac{H_{j}}{\tan \beta}$,

where $H_{s}$ is the thickness of the unconsolidated soil layer; $\varphi$ is the displacement angle of the soil layer; $H$ is the bedrock thickness; and $\tan \beta$ is the tangent of the main influence angle.

(2) Prediction parameters

Based on the results of Sects. 2 and 3, it is apparent that the ratio of soil layer to bedrock, i.e., $H_{\mathrm{s}} / H_{\mathrm{j}}$, is a key factor affecting the ground movement rules. However, because the traditional influence function is hard to predict for the coupled strata of soil and bedrock, we attempted to construct a series of functions incorporating prediction parameters and $H_{\mathrm{s}} / H_{\mathrm{j}}$. This type of function has the form:

$K=f\left[\frac{H_{s}}{H_{j}}, H_{0}\right]$,

where $K$ is one of the prediction parameters; $H_{s} / H_{j}$ is the soil layer to bedrock ratio; and $H_{O}$ is the total mining depth, $H_{O}=H_{s}+H_{j}$. Each prediction parameter function can be obtained as follows:

(1) Subsidence factor $q=a_{1} \frac{H_{s}}{H_{j}}+b_{1}$,

(2) Horizontal displacement factor $b=a_{2} \frac{H_{s}}{H_{j}}+b_{2}$,

(3) Tangent of main influence angle $\tan \beta=a_{3} \frac{H_{s}}{H_{j}}+b_{3}$,

(4) Propagation angle of extraction $\theta=a_{4} \frac{H_{S}}{H_{j}}+b_{4}-c_{4} \alpha$,

(5) Deviation of inflection point $s=a_{5} \frac{H_{s}}{H_{j}}+b_{5} H_{0}$, where $a_{1}$ to $a_{5}, b_{1}$ to $b_{5}$, and $c_{4}$ are constants for a given mining area.

\subsection{Case study}

On the basis of ground observational data for the Lu'an coal group in southern Shanxi, China (Table 1), the prediction parameter function can be established using regression analysis: 
Table 1 Subsidence parameters of observation stations of the Lu'an Group in southern Shanxi, China

\begin{tabular}{llllllllll}
\hline Colliery & Panel No. & $H_{0}(\mathrm{~m})$ & $H_{s}(\mathrm{~m})$ & $q$ & $H_{s} / H_{j}$ & $b$ & Tan $\beta$ & $k_{i}$ \\
\hline Wuyang & 7305 up & 212 & 25 & 0.72 & 0.13 & 0.26 & 2.50 & 0.15 \\
& 7305 down & 212 & 25 & 1.00 & 0.13 & 0.33 & 3.20 & 0.11 \\
& 7309 down & 164 & 20 & 0.72 & 0.14 & 0.30 & 2.70 & 0.13 & 0.9 \\
& 7503 & 318 & 30 & 0.86 & 0.10 & 0.33 & 2.71 & 0.13 \\
& 7506 & 329 & 29 & 0.82 & 0.10 & 0.28 & 2.70 & 0.12 \\
& 7511 & 270 & 40 & 0.86 & 0.17 & 0.31 & 2.70 & 0.14 \\
Wangzhuang & 4326 & 300 & 50 & 0.74 & 0.20 & 0.31 & 2.70 & 0.11 \\
Zhengcun & 2201 & 350 & 62 & 0.82 & 0.22 & 0.25 & 3.60 & 0.6 \\
Sima & 1101 & 242 & 186 & 0.94 & 3.47 & 0.26 & 2.70 & 0.14 \\
Tunliu & 2201 & 540 & 40 & 0.80 & 0.02 & 0.30 & 2.40 & 0.6 \\
\hline
\end{tabular}

Notes $H_{0}$ is the mining depth of the coal seam; $H_{\mathrm{s}}$ is the thickness of the soil layer above bedrock; $H_{j}$ is the thickness of bedrock above the coal seam; $H_{s} / H_{j}$ is the ratio of soil layer to bedrock; $q$ is the subsidence factor; $b$ is the horizontal displacement factor; $\tan \beta$ is the tangent of the main influence angle; $k_{i}$ is the factor of deviation of the inflection point; and $k_{\theta}$ is obtained from the function $\theta=90^{\circ}-k_{\theta} \alpha$, which is the propagation angle of extraction $\theta$ in general geological conditions.

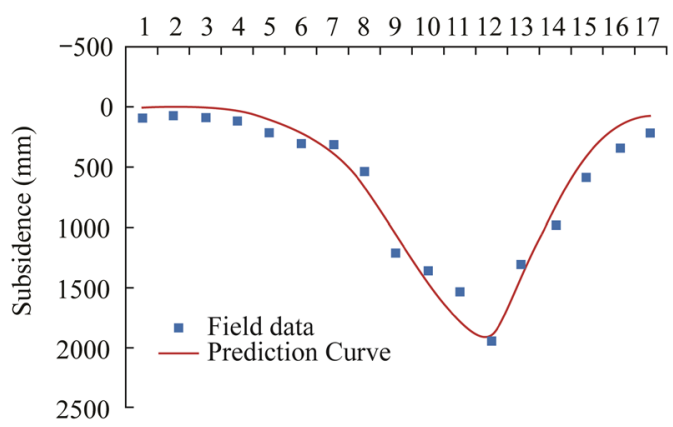

Fig. 17 Difference between predicted and measured subsidence values along the inclined direction of the Wuyang 7506 panel

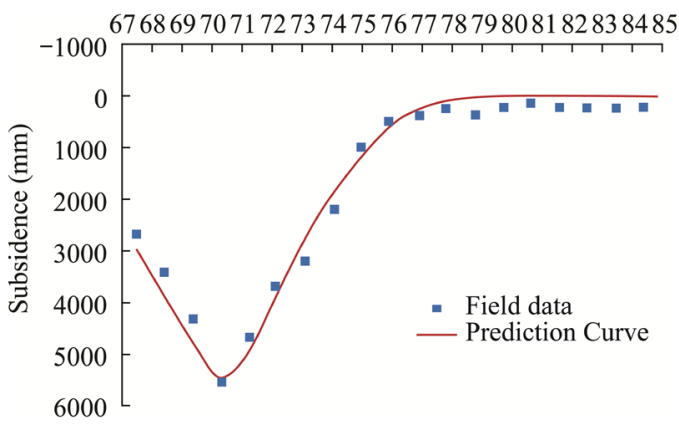

Fig. 18 Difference between predicted and measured subsidence values along the inclined direction of the Sima 1101 panel

$$
\begin{aligned}
& q=0.046 \frac{H_{s}}{H_{j}}+0.74 \quad b=0.03 \frac{H_{s}}{H_{j}}+0.3333 \\
& \tan \beta=-0.1 \frac{H_{s}}{H_{j}}+2.2833 \\
& \theta=77.9-1.407 \alpha+0.45 \frac{H_{S}}{H_{j}} \quad s=0.087 H_{0}+1.07 \frac{H_{s}}{H_{j}}
\end{aligned}
$$

Figures 17 and 18 demonstrate that the predicted results are in good agreement with field data for different thicknesses of the unconsolidated soil layer. The prediction parameters showed in Table 2 .

The standard deviation $m$ of the predictions can be calculated by:

$m= \pm \sqrt{\frac{[V V]}{n-1}}$

where $m$ is the standard deviation of prediction, $\mathrm{mm} ; V$ is the difference between field data and the predicted value, $\mathrm{mm}$; and $n$ is the number of prediction points.

In general, for accuracy of mining subsidence the relative error $m_{d}$ was used:

$m_{d}= \pm \frac{m}{W_{\max }} \times 100 \%$,

where $W_{\max }$ is the maximum subsidence in the field data.

The prediction accuracy of the measurements illustrated in Figs. 17 and 18 are listed in Table 3.

Table 2 Prediction parameters calculated using $H_{s} / H_{j}$

\begin{tabular}{llcccccccc}
\hline Panel No. & $H_{0}(\mathrm{~m})$ & $H_{s}(\mathrm{~m})$ & $H_{j}(\mathrm{~m})$ & $H_{s} / H_{j}$ & $q$ & $b$ & $\tan \beta$ & $\theta$ \\
\hline Wuyang 7506 & 330 & 30 & 300 & 0.10 & 0.76 & 0.33 & 2.27 & 85.2 \\
Sima 1101 & 220 & 171 & 49 & 3.47 & 1.01 & 0.44 & 1.94 & 86.0 & 22.83 \\
\hline
\end{tabular}


Table 3 Accuracy of prediction results

\begin{tabular}{llll}
\hline Panel No. & Standard deviation $(\mathrm{mm})$ & The maximum subsidence $(\mathrm{mm})$ & Relative error $(\%)$ \\
\hline Wuyang 7506 & 131 & 2858 & 4.76 \\
Sima 1101 & 276 & 5565 & 4.96 \\
\hline
\end{tabular}

From Table 3, the relative error of the revised prediction model is less than $5 \%$, which is an acceptable result.

\section{Conclusions}

(1) Based on the geological conditions of the Lu' an coal base in China, two types of mining subsidence simulation were performed: thin bedrock with thick soil layer and thick bedrock with thin soil layer. The results of these two conditions were analyzed.

(2) Two variables, bedrock thickness and soil layer thickness, were studied separately. The results showed that ground deformation will rapidly increase with increasing soil layer thickness, but after a certain value (100 $\mathrm{m}$ in this paper), the ground deformation will change little. When the thickness of the soil layer is constant, surface deformation will decline with increasing bedrock thickness.

(3) On the basis of field data from the Lu'an coal base, the prediction parameters of the influence function can be regressed. Two sets of field data were used to verify the correction of the regression parameter function, and a good match was obtained.

Acknowledgments This project was supported by the National Natural Science Foundation of China (41301469) and the Natural Science Foundation of Shanxi Province, China (2014011001-3).

Open Access This article is distributed under the terms of the Creative Commons Attribution 4.0 International License (http:// creativecommons.org/licenses/by/4.0/), which permits unrestricted use, distribution, and reproduction in any medium, provided you give appropriate credit to the original author(s) and the source, provide a link to the Creative Commons license, and indicate if changes were made.

\section{References}

Dai H, Li W, Liu Y (2011) Numerical simulation of surface movement laws under different unconsolidated layers thickness. Trans Nonferrous Metals Soc China 21(S3):599-603

Guo H, Chen S, Craig MS (2004) Coal mine subsidence simulation using COSFLOW. The AusIMM Bull 2:50-52

Ji H, Yu X (2011) Research on numerical simulation of mining subsidence. Appl Mech Mater 148:384-387

Wang S, Fu Z, Liao J (2008) Study on dynamic numerical simulation of overburden movement mining under railways. Journal of Coal Science and Engineering (China) 1:29-33

$\mathrm{Xu}$ N, Kulatilake PH (2013) Surface subsidence prediction for the Wutong mine using a 3-D finite difference method. Comput Geotech 48:134-145

$\mathrm{Xu} \mathrm{W,} \mathrm{Li} \mathrm{Y} \mathrm{(2012)} \mathrm{Numerical} \mathrm{simulation} \mathrm{of} \mathrm{safe} \mathrm{strip} \mathrm{mining} \mathrm{under}$ thick unconsolidated layers. Appl Mech Mater 182-183:941-944

Yang F, Chen S (2011) Numerical simulation of compound media coupling mechanism of deep mining overburden strata. Trans Nonferrous Metals Soc China 21(S3):631-636

Yang W, Xia X (2013) Prediction of mining subsidence under thin bedrocks and thick unconsolidated layers based on field measurement and artificial neural networks. Comput Geosci 52:199-203

Zhang H, Zhang G, Shen Y (2012) Mechanism and prediction research of the surface mining subsidence of thick loose layers in mining area. Appl Mech Mater 204-208:3488-3493

Zhou D, Wu K, Cheng G (2014) Mechanism of mining subsidence in coal mining area with thick alluvium soil in China. Arab J Geosci 8:1855-1867 